\title{
Adapting the E-course for Teacher Training in the Teacher Professional Development System
}

\author{
Leonid Doliner*, and Vladimir Nazarov \\ Ural Federal University, Sverdlovsk Region Institute for Educational Development, Ekaterinburg, \\ Russian Federation
}

\begin{abstract}
In modern educational system reform in Russia, there is a deepening contradiction between the required and real level of professional competence of teachers. One way to overcome this contradiction is the systematic professional development of the teaching staff implemented with the help of distance learning technologies (DLT). One of the means to ensure high quality of training is course evaluation by trainees. It allows for motivation and a high level of training, to understand the directions of the course modification. At the same time, teachers themselves are professional experts in training, and their assessment of the e-course may be more objective than that of the trainees of other professions. Additional vocational education is primarily characterized by a high degree of applied orientation to modern learning technologies. Such are the realities that changes, especially in digital technology in education, are changing rapidly. And it is so fast that, in fact, one person cannot be aware of the full range of directions in which they (the changes) are taking place. This problem can be solved using the DLT through systematic modification of the e-course. The object of the study in this paper is the process of teachers' training in the system of professional development of pedagogical staff using distance learning technologies. The subject of the study: the mechanism of optimization of elearning distance learning courses used in the system of professional development of pedagogical staff. Research purpose: to identify mechanisms to optimize the effectiveness of e-courses to increase trainees' motivation, correlation of theory content with practice with the help of trainees themselves under conditions of synergetic approach [1]. Research objectives: a) to identify parameters for improving the effectiveness of ecourses; b) to develop a toolkit for improving the effectiveness of e-courses; c) to develop recommendations for improving the effectiveness of e-courses. The method used in the study is the analysis of pedagogical literature, Google-form-based questionnaire, synthesis, and generalization. The novelty of the study is related to the creation of conditions for modifying ecourses for teachers' professional development through the examination of the course by the teachers themselves. This article is written within the framework of the Russian Foundation for Basic Research project 19-2914176 "Building a Fundamental Model of Digital Transformation of the
\end{abstract}

\footnotetext{
*Corresponding author: dolis13@rambler.ru
} 
General Education System Using a Digital Platform for Results-Based Education".

\section{Introduction}

The system of Russian education at the present stage of social development is undergoing significant changes. But whatever reforms are underway, they end up focusing on a specific performer - the teacher. It is the teacher who is the main figure in putting innovations into practice. In order to do so, he or she must have the necessary level of professional competence.

The federal-state educational standards set the requirements to the conditions for the implementation of basic general education programs in terms of the qualification level of teaching staff following the qualification characteristics of the relevant position. Its structure includes basic knowledge, abilities, skills necessary and sufficient to act successfully. Obviously, in a dynamic, evolving society, it is impossible to achieve the right level of qualification once and for all. This demonstrates the necessity of professional development as a form of value- and semantic, content, and technological enrichment of the system of professional activity.

In modern conditions of education reform in Russia, there is a deepening contradiction between the required and actual level of professional competence of teachers.

One way to overcome this contradiction is the system of professional development of pedagogical staff, implemented through various forms of training. Changing requirements for the level of training of teachers, the introduction of federal educational standards set the task of rapid adaptation and systematic professional development of teaching staff. If previously advanced training was carried out once every five years, in accordance with the Federal Law "On Education in the Russian Federation" [6] - every three years. On the one hand, it is very relevant in the wide implementation of innovations, which the teacher needs to know and use in the educational process. On the other hand, there is a considerable increase in the workload of the in-service teacher training system, which is not always ready for an increase in the cohort of students. One of the ways to solve this problem is the introduction of e-learning and distance learning technologies (DLT).

It would seem that the current trends of DLT implementation based on the electronic distance learning course (EDLC) make it fairly easy to implement professional development in a distance format. But there were some pretty serious problems:

- "traditional" e-course including a chain "theory (text or video lecture) $\rightarrow$ test $\rightarrow$ theory $\rightarrow$ test...)" does not work for a number of reasons. One of the most significant is the actual duplication of work with the textbook with a minimal level of control. Teachers are not ready to read a "thick" textbook. They focus on technologies that can be used immediately in the classroom;

- "traditional" e-course, on the one hand, does not include (or includes minimal) feedback, which provides zero learning outcomes;

- another extreme has also emerged: to implement a course using "distance tutoring" technology, when classes are held only through virtual interaction. This approach is not rational as it requires the same amount of teacher's time as in full-time education (which means a significant increase in funding), and it is also necessary to gather all trainees at the workplace at the same time, which is practically impossible;

- obviously, the solution is somewhere in the middle: to develop an effective EDLC that has elements of automated learning and interaction aspects that will provide a real process of managing the learning activities of the trainees. 
If the optimal solution for DLT technology was theoretically found (see item 4), then it turned out to be quite problematic to determine the technology for objective course evaluation according to various parameters. And it is required not just to evaluate the course but to evaluate it from the listeners' point of view and to understand the directions of its modification.

Evaluation and selection of modification directions of any educational system are associated with a large number of subjective factors. This is why any formal technology does not always lead to the right result. We suggested that the solution could be the use of a synergistic approach. Without going into detail, let us explain its essence.

The problems described above have quite objective reasons. The fact is that additional professional education for teachers is characterized primarily by a high degree of applied orientation towards modern learning technologies. Change, especially in the use of IT technology, is happening extremely fast. Moreover, so fast that it is virtually impossible for one person to keep abreast of all the innovations and the full range of directions in which change is taking place.

This situation leads to the choice of one of two solutions. The first (traditional) is to choose fundamentals, which change much less frequently than practices, and teach them. The second one is to constantly change the teaching content, adapting to changes in technology. At first glance, the second solution is more progressive. But the first one is mainly chosen because the second one is very difficult to implement technically due to the limited capabilities of one person (or group of people). It is unlikely that an educational organization is ready to allocate a whole group of content developers who are able to provide permanent monitoring of scientific and applied research to incorporate it into the learning content. And professional development of teachers implies just the second solution, since the first one, as it is commonly believed, was implemented in the university.

One of the ways out of this situation is the use of a synergetic approach as the basis of modern education, implementing the training of students as an element of self-organizing chaos.

While in full-time supplementary professional programs (FTP) this is unlikely (little time, much information, need to do tasks), the situation is different in DLT conditions. The ecourse should strike a balance between theory and practice. It is difficult to achieve such a balance from the outset. A possible solution is to involve trainees in the expertise of theorypractice ratio, correction of theory scope, optimization of practice, correction of the control system, etc. We need to use the situation where we train teachers who are professionals and practitioners.

Many researchers have paid and are paying serious attention to the quality of learning content [4, 15, 17]. In particular, [17] discusses, among other things, evaluating the quality of an e-course. The author concludes that to assess the quality of an e-course, "two approaches are used: holistic and multilayered". Evaluating "as a whole" uses several general criteria (e.g., security, productivity); standards compliance checking; and user feedback.

As practice shows, this approach is not sufficient to make major adjustments and modernize the system. The second approach is used more often for adaptive e-learning systems. In them, the final result is influenced directly by the adaptation mechanisms used. The EOS itself consists of various subsystems that interact with each other. Different sets of criteria for each subsystem are used to assess quality $[7,11]$. In this way, the entire learning process is diagnosed, deficiencies and risks are more fully identified, and targeted corrections are developed."

Despite the attention to the analysis of evaluation methods and tools for e-courses offered in current research, we have not been able to find a sufficiently effective application tool to ensure the adaptation of e-courses to the needs of a particular category of trainees.

Based on all of the above, the following research questions can be formulated: 
- what is the mechanism for adapting e-courses to the category of trainees of professional development courses?

- can the results be generalized for the subsequent modernization of various e-courses by identifying a mechanism for adapting e-courses?

In this article, we will try to answer these questions and propose approaches to adapting the e-course with the help of the students themselves.

\section{Materials and Methods}

Study purpose: to identify mechanisms to improve the effectiveness of e-courses under a synergetic approach.

Study objectives:

a) Identification of factors for enhancing the effectiveness of e-courses;

b) developing tools to enhance the effectiveness of e-courses;

c) developing recommendations for enhancing the effectiveness of e-courses.

Methods used in the research: analysis of pedagogical literature, questionnaires based on Google forms, synthesis, and generalization.

The questionnaire is part of the e-course, with a separate questionnaire designed for each section of the course (the section usually included both theoretical block (blocks), practical block, and control system), focused on a detailed assessment. The questionnaire, in addition to questions on the evaluation of training materials, included questions related to the comfort of learning, motivational component, the level of assimilation, etc. The questionnaire was anonymous and was filled in at the request of the student. The e-course under which the study was conducted is called "Modern Distance Learning Technologies".

\section{Results}

\subsection{Identifying how to access e-course sessions}

One of the problems that arose during the study was the degree of freedom of access to the resources (lessons) included in a particular e-learning distance learning (EDLC) course.

Access options include:

- arbitrary access to any resource at any time;

- restriction of access to resources (one or more) by date and time of execution;

- the limiting access to resources depending on the results of previous sessions.

The second option was immediately ruled out, as trainees of additional professional development programs cannot or are not able in principle to comply with any deadlines.

Only the first and third access options were used during the study. About 250 people took part in the survey of the additional professional development program for teachers "Modern Distance Learning Technologies" (12 groups), implemented with the help of an electronic distance learning course of the same name. Here are the statistics of the most characteristic indicators.

Table 1. Dynamics of learning outcomes depending on the type of access to EDLC resources.

\begin{tabular}{|c|c|c|c|c|c|c|c|c|c|}
\hline Group & \begin{tabular}{|c|} 
Total \\
persons
\end{tabular} & $\begin{array}{l}\text { Acces } \\
\text { s type }\end{array}$ & \multicolumn{2}{|c|}{ Didn't learn } & $\begin{array}{l}\text { Finishe } \\
\text { d the }\end{array}$ & \multicolumn{2}{|c|}{$\begin{array}{l}\text { Finished on } \\
\text { time. }\end{array}$} & \multicolumn{2}{|c|}{$\begin{array}{c}\text { Finished after } \\
\text { the course }\end{array}$} \\
\hline $\begin{array}{c}\text { EDLC } \\
\text { cohort } 5\end{array}$ & 23 & 1 & 3 & $004 \%$ & 20 & 7 & $035 \%$ & 13 & $65.00 \%$ \\
\hline
\end{tabular}




\begin{tabular}{|c|c|c|c|c|c|c|c|c|c|}
\hline $\begin{array}{c}\text { EDLC } \\
\text { cohort 6 }\end{array}$ & 21 & $1+3$ & 2 & $019 \%$ & 19 & 6 & $032 \%$ & 13 & $68.42 \%$ \\
\hline $\begin{array}{c}\text { EDLC } \\
\text { cohort } 7\end{array}$ & 25 & 3 & 2 & $012 \%$ & 23 & 17 & $074 \%$ & 5 & $21.7 \%$ \\
\hline
\end{tabular}

The type of access in all EDLCs was traditionally free (except for EDLC cohort 6 and EDLC cohort 7). However, it turned out that the freedom could be enjoyed by a very limited circle of listeners. Virtually all cohorts turned out to have educators who are unable to learn remotely. Most can't organize themselves to get started. There were many reasons for that: they just wanted to get a certificate, and for that, they had to work hard; there was a big workload, they did not expect that so much effort would be required ("... they did not know that it was so difficult to study remotely"), and so on. Of course, there were also force majeure situations: the teacher quit the school and moved to another area, got sick; the teaching load was sharply increased, etc.

Conclusion: in order to meet the target graduation rate, the number of students enrolled in the group should be 2-4 persons more than planned.

Table 2. Learning outcomes through ECDL depending on course structure and type of access.

\begin{tabular}{|c|c|c|c|c|c|c|c|c|}
\hline Group & $\begin{array}{c}\text { Finished } \\
\text { the } \\
\text { course in } \\
\text { total. }\end{array}$ & $\begin{array}{c}\text { Acces } \\
\text { s type }\end{array}$ & \multicolumn{2}{|c|}{$\begin{array}{c}\text { Missed at least } \\
\text { one section }\end{array}$} & \multicolumn{2}{|c|}{$\begin{array}{c}\text { Number of } \\
\text { classes for } \\
\text { credit }\end{array}$} & \multicolumn{2}{|c|}{$\begin{array}{c}\text { Number of sessions } \\
\text { per evaluation }\end{array}$} \\
\hline $\begin{array}{c}\text { EDLC } \\
\text { cohort 5 }\end{array}$ & 20 & 1 & 19 & $095 \%$ & 6 & $046 \%$ & 7 & $054 \%$ \\
\hline $\begin{array}{c}\text { EDLC } \\
\text { cohort 6 }\end{array}$ & 19 & $1+3$ & 14 & $074 \%$ & 3 & $021 \%$ & 11 & $079 \%$ \\
\hline $\begin{array}{c}\text { EDLC } \\
\text { cohort 7 }\end{array}$ & 23 & 3 & 0 & $0 \%$ & 0 & $000 \%$ & 11 & $100 \%$ \\
\hline
\end{tabular}

As the table shows, where there is a "credit" class, a fairly high percentage of trainees who missed that class was identified. It can be hypothesized that this is not related to the type of class ("credit" or "assessment"), but rather to the fact that credit classes can be skipped and proceed to the next class.

The data presented in Tables 1 and 2 allowed drawing the following conclusions: limiting access to e-course sessions (one cannot start a session without completing the previous one) allows disciplining the trainees and increases the proportion of trainees who finish the learning process on time.

\subsection{Identifying approaches to modifying the e-course}

Two objectives were addressed at this stage of the study.

Can trainees be involved in modifying the e-course?

Is it possible to have the content of an e-learner reviewed?

The solution to these problems was implemented by means of questionnaires. As already noted, the questionnaires were developed for a specific e-course "Modern Distance Learning Technologies", which includes 6 sections. A separate questionnaire was developed for each section + a questionnaire for the course as a whole. As part of the questionnaire, students were involved in evaluating the section materials, identified the correlation of theory and practice, the availability of opportunities to make changes in the content of both sections, and the e-course as a whole.

Questionnaires for each section had a fairly uniform structure and allowed not only to evaluate the components of the section (training module, information resource, simulator, test, etc.) but also to find out the attitude to these materials: understandable or not, what is 
learnt, what is not learnt. The trainees were also invited to make suggestions for adjusting the content of the training materials.

The content of each section was restructured based on the comments and suggestions of the trainees. A questionnaire was then administered to the following groups of trainees. When there were no comments noted previously, the section was considered to be adapted to that category of trainees. It was concluded that involving trainees in the examination and modification of the e-course is extremely important and rational, as it contributes to the optimization of the content and the enhancement of learning outcomes.

The approach allowing learners to reflect on each section of the course allowed for a fairly rapid (no more than 3 iterations) optimization of the course and its adaptation to a specific category of trainees.

The result of the final questionnaire on the course is interesting. First, the training and questionnaires took place before the pandemic, and distance learning technologies were not taken seriously by teachers. Secondly, there were not more than $10 \%$ of listeners who were intentional about mastering distant technologies. The bulk of the teachers enrolled in the professional development course for the certificate, its content was secondary.

Number of respondents who answered the final questionnaire - 93. The first question of the questionnaire was aimed at identifying the pedagogical experience of the trainees:

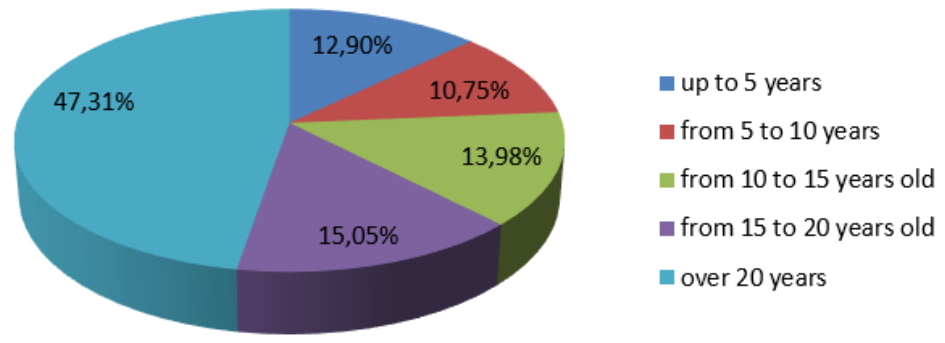

Fig. 1. Teaching experience of trainees

The distribution by the length of service is quite close to the real structure of teachers in educational organizations of the Sverdlovsk region. Not the most optimistic figure $-47.31 \%$ have more than 20 years of experience.

The next question was of a generalized nature and read as follows: "In your opinion, was the training in the course "Modern Distance Learning Technologies" useful for you? We got the following result: 


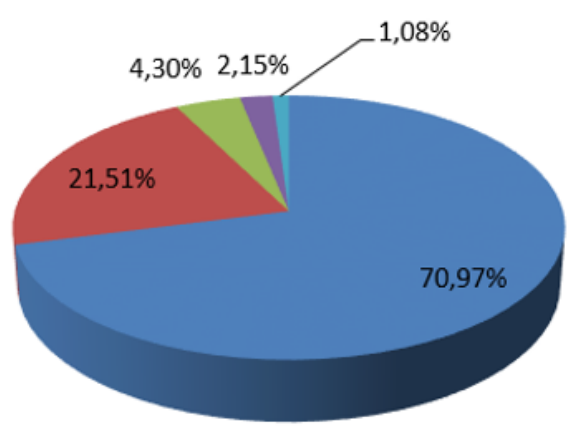

- Yes, undoubtedly

Rather yes than no

More likely no than yes (i.e. there is a result, but it does not mean so much to me)

No, it's no use to me

I am at a loss to answer

Fig. 2. Trainees' assessment of the usefulness of the FTP training

The figure is quite high: $92.47 \%$ felt that the training was useful and effective for them.

Interesting, from our point of view, is the result of integrating the previous two diagrams, with the help of which we tried to answer the question about the usefulness of the professional development course "Modern Distance Learning Technologies" for teachers depending on their seniority.

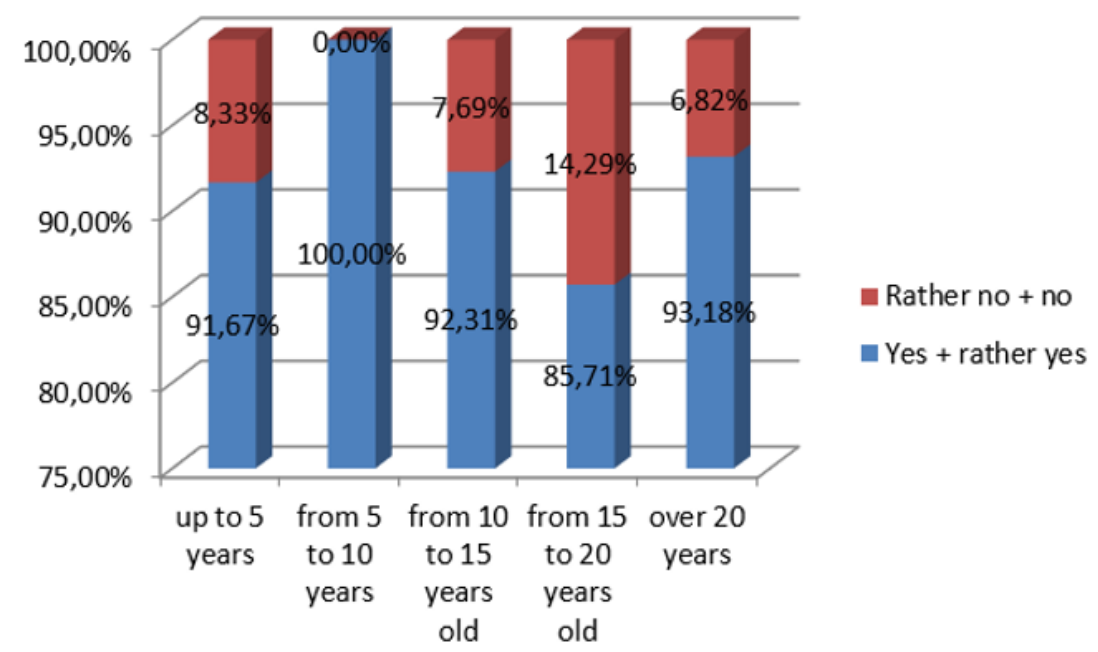

Fig. 3. Analysis of the usefulness of DFS for the trainee depending on the length of service

The result was quite unexpected. We hypothesized that there is a predominantly inverse proportional relationship between age and learning success: the younger, the more capable of learning. Respondents with 5 to 10 years of experience were found to be the most successful in terms of learning outcomes. And the most unsuccessful are those whose length of service varies from 15 to 20 years. Interestingly, they are less successful than teachers with more than 20 years of experience! Even more unexpectedly (especially in the digital-related field), teachers with more than 20 years of experience are more successful in their studies than young people with less than 5 years of experience!

The next question was related to the trainees' evaluation of their learning in the course. These statistics were mainly for the final groups that were questioned at the end of the study. 


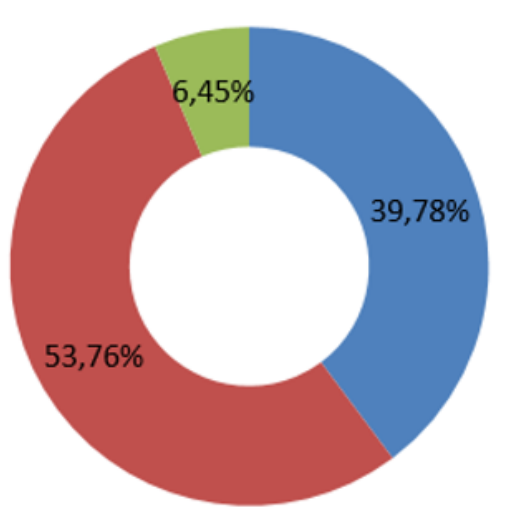

- Learned (got an idea) to do courses

Acquainted with new technology, increased literacy

The educational institution is not ready to introduce additional education

Fig. 4. The main result of the training within the FTP of PC "STDO"

The result was $100 \%$. Even those who were not motivated to learn (who were convinced of the pointlessness of learning in this area) still mastered the technology.

The data on the willingness of the trainees to design an e-course is as follows:

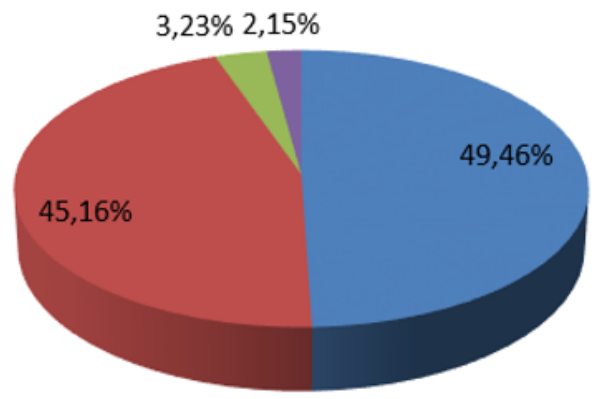

\author{
a In general, I think I'm \\ ready \\ neady but at the level of \\ individual elements \\ Rather not ready \\ Not ready
}

Fig. 5. Self-assessment of teachers' readiness to design e-learning courses

The result was $94.62 \%$. The result is quite high. It is possible to put forward a hypothesis that the level of computer literacy of the trainees does matter.

In assessing their willingness to use the distance learning system they were taught to work with for learning purposes in their educational organization, the following judgments were made: 


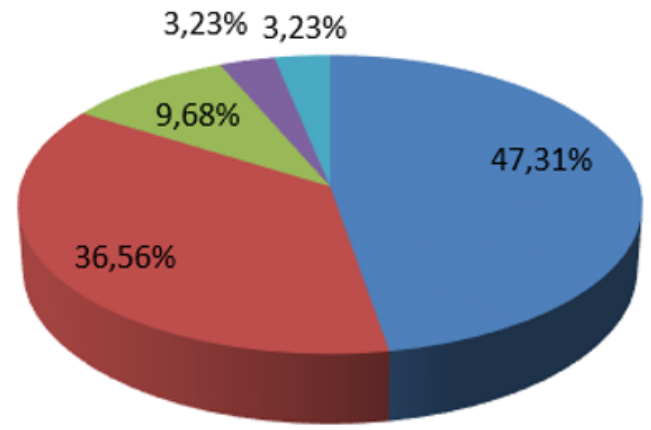

- In general, I think I'm ready

Ready but at the level of individual elements

Rather not ready

\section{Not ready}

I am at a loss to answer

Fig. 6. Trainees' assessment of their readiness to teach supplementary education in the Distance learning system

Here $83.87 \%$ of respondents considered themselves ready.

The next significant question was related to the trainees' evaluation of the use of the acquired knowledge and skills in their pedagogical activities.
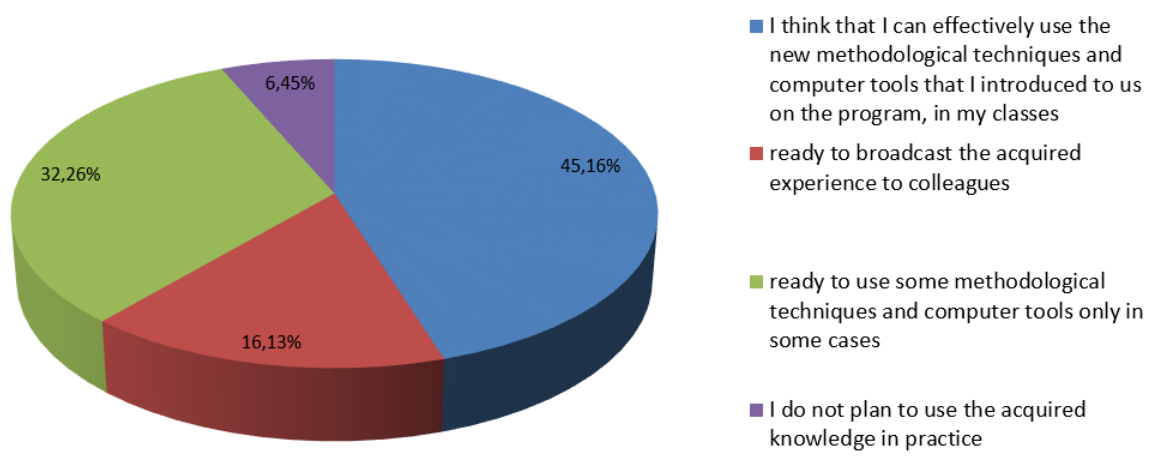

Fig. 7. Plans of trainees to use the knowledge and experience gained at the programme in their professional activities

One of the key objectives of the additional professional development program "Modern Distance Learning Technologies" is the organization of distance learning within the Sverdlovsk Region (and probably not only) with a unified approach and within a unified system (UDS) on the basis of the Institute of Education Development of the Sverdlovsk Region. Judging by the self-assessment of trainees, the task is solved quite successfully, since the vast majority of trainees $(93.55 \%)$ intend either to use the DLS in their work, or share the experience gained with colleagues, or use it in their teaching practice (which, however, is also very important).

\section{Discussion}

Studies related to the implementation of distance learning technologies focus mainly on recommendations for creating e-courses $[8,11,12,13,16,19]$. The recommendations made in these studies are quite reasonable and justified. However, as our experience in creating e- 
courses and analysis of a fairly large range of ready-made resources has shown, even meticulous implementation of the most correct recommendations does not guarantee that the developed e-course provides quality learning. Quite a lot depends on both the creators of such courses and the trainees. Course-specific improvement iterations have shown that:

- it is problematic to create an ideal e-learning course that would give $100 \%$ results because trainees on the course have different initial training, different interests, and motivation. It is possible to optimize, but it is still just a dream to bring it to perfection;

- distance learning technologies in adult education are focused on a fairly high level of selflearning. The obtained statistics show that not more than $30 \%$ of teachers possess this skill at the required level;

- Unfortunately, less than $50 \%$ of teachers also have the elements of analysis and critical thinking;

- there are problems that are related to organizational and technical issues. In particular, time management problems: quite a large number of trainees are not ready to combine work and distance learning. On the technical part, it turned out that, first, not all teachers have sufficient digital literacy and access to high-speed Internet.

\section{Conclusion}

It can be stated that the research objective has been generally implemented: the mechanism of enhancing the efficiency of e-courses, which is based on the synergetic approach and consists in attracting trainees enrolled in the programs of professional development of teaching staff using DLT, based on EDLC, has been proposed. Anonymous surveys are used as such a mechanism, focused on the expertise of trainees on various aspects of training, including EDLC components. This approach increases the trainees' motivation and aims to correlate theory with practice through the trainees themselves.

The key parameters for improving the effectiveness of the FTP and the EDLC used within it are:

- openness of the system to evaluate the content, practice, teachers' work, and other aspects of the activities in which trainees take part;

- compliance by teachers and developers of EDLCs with all the requirements they themselves have for the materials they create;

- correlation between the theoretical part of the FTP and the practical part, which ensures the practice-oriented nature of the FTP itself;

- variational and correct tests used in the EDLC framework;

- mobility in modifying the EDLC based on trainees' comments;

- taking [reasonable] comments from the previous group into account when teaching the next group.

A toolkit for improving the efficiency of EDLC in a synergistic approach:

- anonymous surveys after each section of the ECDL and a final survey at the end of the course, in which trainees act as experts;

- permanent correction based on the analysis of the comments made. It should be borne in mind that the reasons for comments made may be quite different and should be ascertained before correcting an e-course;

- clear targeting of learning outcomes will avoid a great deal of misunderstanding;

The study was carried out on the basis of an additional professional training program for teachers "Modern Distance Learning Technologies", implemented through e-learning course of the same name.

\section{References}


1. N. A. Alekseev, Reflections on synergetic in Pedagogy: Education and Science 6 (30), 103 (2004)

2. S. Bennett, L. Lockyer, Becoming an Online Teacher: Adapting to a Changed Environment for Teaching and Learning in Higher Education (2004). https://www.researchgate.net/publication/236667492_Becoming_an_Online_Teacher_ Adapting_to_a_Changed_Environment_for_Teaching_and_Learning_in_Higher_Educ ation

3. M. Burns, Distance Education for Teacher Training: Modes, Models, and Methods (2011). https://www.edc.org/sites/default/files/uploads/Distance-Education-TeacherTraining.pdf

4. Z. Djoub, Teacher development: What Teachers Need to Know (2021). https://edulearn2change.com/article-teacher-development-what-teachers-need-to-know/

5. A. Elliott, Remote Professional Development For Teachers (2021). https://dc.wondershare.com/screen-recorder/professional-development-for-teachersremote-learning.html

6. Federal Law No. 273-FZ of 29.12.2012 (as amended on 24.03.2021) «On Education in the Russian Federation». https://yandex.ru/turbo/zakonrf.info/s/zakon-ob-obrazovaniiv-rf/

7. S. A. Kornienko, E-learning as a means of implementing an educational program. Pedagogy: traditions and innovations: materials of the V International Scientific Conference (Chelyabinsk, June 2014). Vol. 0. Chelyabinsk : Two Komsomolets, 175 (2014). https://moluch.ru/conf/ped/archive/104/5759/

8. Methodological recommendations for the development of an electronic training course, 2017. Retrieved from http://do.mrsu.ru/documents/rekomend.pdf.

9. V.L. Nazarov, L.I. Doliner, Digital transformation of schools in the context of a pandemic: the experience of the Sverdlovsk region. Ekaterinburg, Russia: Ural Federal University

10. V.L. Nazarov, L.I. Doliner, G.A. Butakova, Aspects of distance learning implementation in regional educational institutions/ International Conference on Economic and Social Trends for Sustainability of Modern Society - ICEST-2020, Krasnoyarsk - Saint Petersburg (2020)

11. Pyatnitskaya, M. (2020). How to create an online course for teachers from scratch. Retrieved from https://brl.mk.ru/science/2020/11/13/kak-sozdat-onlaynkurs-dlyauchiteley-s-nulya.html

12. Requirements for e-learning courses. (2018). http://sdo.bashedu.ru/mod/page/view.php?id=44452

13. Scientifically-based recommendations on the use of online courses in the implementation of educational programs of higher education, 2017. Retrieved from http://fgosvo.ru/uploadfiles/metod/67_6014_URFU.pdf

14. Selecting and adapting learning resources for teachers: Case studies (n.d.). https://www.teachingenglish.org.uk/article/selecting-adapting-learning-resourcesteachers-case-studies

15. S. N. Usova, Hypotheses, discussions, reflections: a scientific and theoretical j. 1(42), (2020)

16. T. G. Vezirov, Int. J. of Humanities and Natural Sciences 3(36), 15 (2018).

17. T. B. Volobueva, Int. J. of Humanities and Natural Sciences 4(25), 11 (2015) 
18. A.S. Yucel, E-learning approach in teacher training (2006). https://files.eric.ed.gov/fulltext/ED494378.pdf

19. V. I. Zhukova, Int. J. of Humanities and Natural Sciences 10-1, 73 (2018) 